\title{
Disreflexia autonómica en cirugía de columna cervical
}

\author{
Deambrosi MV. ${ }^{1}$, Durán Chávez PD. ${ }^{1}$, Cianferoni JL. ${ }^{1}$, Deltrozzo JO. ${ }^{1}$, Bolzón I. ${ }^{1}$
}

1 Hospital Regional Dr. Ramón Carrillo, Santiago del Estero, Argentina.

Introducción: Reportamos caso de disreflexia autonómica (DA) en paciente con trauma cervical alto de seis días de evolución.

Caso clínico: Paciente masculino de 21 años, ingresa a quirófano para cirugía programada instrumentación de columna cervical, diagnóstico luxo-fractura de C5 tras traumatismo vial de moto.

Paciente lucido, vigil, orientado en tiempo y espacio, cuadripléjico, sensibilidad conservada a $3 \mathrm{~cm}$ superior de linea intermamilar, refiere drogadicción y tabaquismo. Preoperatorio registro inicial:TA:103/54 mmHg Fc: 60 lxm So2 98\%. Se instaura plan anestésico: posición en olfateo, preoxigenación Fio2 100\% durante 3 minutos e inducción secuencia rápida: propofol y succinilcolina. Se procede realizar intubación con videolaringoscopio con Introductor de Eschmann infructuoso, segundo intento laringoscopio McCoy rama 4, intubación con tubo espiralado exitosa, ARM modo vcv, Fio2: 0,30, Vt: 0.400 Peep: 6 Fr: 12 I: E 1:2,5 Etco2: 35 mmHg t $36,4^{\circ} \mathrm{C}$, diuresis inicial:100ml. Mantenimiento: sevofluorane, remifentanilo y atracurio. Luego de 15 minutos, registro hemodinámicos intraoperatorios tormentosos que varian TA: 210/90 -180/85 mmHg Fc: 45-110 lxm, coincidiendo con toma de injerto óseo en cresta iliaca. Después de 30 minutos, estabilidad hemodinámica. Duración acto quirúrgico 3 horas. Diuresis final: $1.250 \mathrm{ml}$. Egresa paciente a servicio de Unidad de Terapia Intensiva.

Discusión: La DA es la desregulación del sistema nervioso autónomo que conduce a una respuesta autónoma descoordinada que puede resultar en un episodio hipertensivo potencialmente mortal. Se desarrolla típicamente después de una lesión torácica alta o completa, superior a T6, a este nivel existe perdida del control supraespinal sobre las neuronas preganglionares simpaticas (SPN) caudal a la lesión, lo que hace que las SPN sean susceptibles a episodios de hiperactividad resultantes de estímulos por debajo del nivel de lesión, sin un control supraespinal descendente, generando inestabilidad vascular extrema.

Los factores que desencadenan esta inestabilidad implican hipertono noradrenérgico y motor, puede ser un estímulo cutáneo, propioceptivo o visceral; el $85 \%$ se debe a distención vesical. Generando ascensos del $20 \%$ presión arterial media basal o aumentos superiores de $150 \mathrm{mmHg}$ de presión sistólica, acompañado de bradicardia o taquicardia en lesiones cervicales altas. Generalmente se desarrolla entre un mes a un año de producido el trauma, pero se ha descripto en primeros días o semanas.

Conclusión: Dado que el funcionamiento del sistema nervioso simpático en estos pacientes no se puede predecir, se sugiere una inducción suave y lenta de la anestesia. Si presenta hipertensión debe pensarse en forma inmediata en una DA y realizar la búsqueda y manejo del evento desencadenante como inicio del tratamiento, profundizar acto anestésico seguido de vasodilatadores de acción rápida.

https://doi.org/10.25237/congresoclasa2019.82 